\title{
Qualidade Física e Fisiológica de Sementes Comercializadas de Capim-Colonião em Campo Grande - MS
}

\author{
Physical and Physiological Quality of Seeds of Guinea Grass Commercialized in Campo \\ Grande - MS
}

\author{
Silvia Rahe Pereira*a; Adriana Paula D’Agostini Contreiras Rodrigues's; Daiane Rodrigues Oliveira ${ }^{\text {a; }}$ Valdemir Antônio \\ Laura $^{\text {ab }}$; Daniela Aparecida Dalla-Costa ${ }^{\mathrm{c}}$ \\ aUniversidade Anhanguera-Uniderp, Programa de Pós-Graduação Stricto Sensu em Produção e Gestão Agroindustrial. MS, Brasil. \\ bUniversidade Federal de Mato Grosso do Sul, Programa de Pós-Graduação Stricto Sensu em Biologia Vegetal. MS, Brasil. \\ 'Universidade Tecnológica Federal do Paraná. PR, Brasil. \\ *E-mail: silviarahe@gmail.com
}

\begin{abstract}
Resumo
O Centro-Oeste brasileiro representa a região brasileira com maior área e produção de sementes de Megathyrsus maximus, uma gramínea muito utilizada para a formação de pastagens em regiões tropicais do Brasil e outros países da América. Objetivou-se no presente estudo diagnosticar a qualidade física e fisiológica de sementes de três cultivares da espécie M. maximus (Mombaça, BRS Tamani e BRS Zuri) comercializadas por diferentes empresas de Campo Grande (MS). Os experimentos foram conduzidos utilizando-se sementes da safra 2017-2018 em um delineamento inteiramente casualizado, em esquema fatorial $3 \times 6$, avaliando-se três cultivares e seis procedências. As variáveis analisadas foram: pureza física, peso de mil sementes, primeira contagem do teste de germinação, germinação, valor cultural e teste de tetrazólio. Os resultados encontrados demonstram que, com exceção de um lote da cultivar Mombaça, os demais lotes das três cultivares da espécie Megathyrsus maximus (Mombaça, BRS Tamani e BRS Zuri), de todas as procedências avaliadas, apresentaram qualidade física e fisiológica compatível com a comercialização em função da legislação vigente. No entanto, é possível encontrar lotes com qualidade distinta no mercado de Campo Grande. Assim, a escolha adequada da procedência (empresa) vai garantir a expressão máxima do potencial genético, subsidiada por processos adequados de produção e pós-colheita.
\end{abstract}

Palavras-chave: Megathyrsus Mombaça. Gramíneas Tropicais. Teste de Germinação. Teste de Tetrazólio. Valor Cultural.

\begin{abstract}
Brazilian's Midwest represents the region with the largest area and production of Megathyrsus maximus seeds, a grass widely used for the pastures formation in tropical regions of Brazil and other countries in America.The objective of this study was to diagnose the physical and physiological quality of seeds of three cultivars of the species Megathyrsus maximus (Mombaça, BRS Tamani and BRS Zuri) commercialized by different companies of Campo Grande (MS). The experiments were conducted using seeds of the 2017-2018 harvest, in a completely randomized design, using a factorial scheme $3 \times 6$, with three species and six sources, totaling 18 treatments. The variables analyzed were: physical purity, weight of one thousand seeds, first count of germination test, germination, cultural value and tetrazolium. The results showed that with the exception of one lot of cultivar Mombaça, the other lots of the three cultivars of species Megathyrsus maximus (Mombasa, BRS Tamani and BRS Zuri), of all provenances, have compatible physical and physiological quality with marketing in accordance with current legislation. However, it is possible to find lots of different quality in the Campo Grande market. Thus, the appropriate choice of source (company) will guarantee the maximum expression of genetic potential, subsidized by adequate production and post-harvest processes.
\end{abstract}

Keywords: Megathyrsus mombaça. Tropical Grasses. Germination Test. Tetrazolium Test. Cultural Value.

\section{Introdução}

O capim-colonião [Megathyrsus maximus (Jacq.) B. K. Simon \& S. W. L. Jacobs sin. Panicum maximum] é uma gramínea forrageira originária da África tropical, muito utilizada para a formação de pastagens em regiões tropicais do Brasil e outros países da América (GARCEZ et al., 2016). Apresenta diversas características agronômicas favoráveis como: alta capacidade de produção de matéria seca, alto teor de proteína, facilidade de estabelecimento, aceitabilidade pelos animais, capacidade de emissão de perfilhos vigorosos e tolerância à seca (MENDONÇA et al., 2014; MELO et al., 2016). Esta última característica tem motivado uma demanda expressiva por sementes deste gênero (CANTO et al. 2012; MELO et al., 2016).

A importância das sementes de colonião teve início a partir de 1972 (MASTROCOLA; MARCOS-FILHO, 1984), sendo considerada por muitos pecuaristas uma das forrageiras mais produtivas. Apresenta potencial de produção de massa seca de 8 a 12 t/ha/ano (STABILE et al., 2010) com elevado valor nutricional, que garantem a obtenção de animais mantidos a pasto com alto desempenho (LIMA et al., 2018). Por isso, apresenta-se como a segunda gramínea forrageira em importância quanto ao volume de sementes comercializadas no Brasil, com produção estimada de sementes nas safras de 2015/2016 de 34 mil toneladas de sementes produzidas em 21 mil hectares (ABRASEM, 2019).

Os padrões e normas que regem a produção e comercialização de sementes de espécies forrageiras, e os atributos de qualidade para comercialização destas, são assegurados pela Lei 10.711 de 5 de agosto de 2003 
(BRASIL, 2003), e Instruções Normativas - IN do Ministério da Agricultura Pecuária e Abastecimento - MAPA. A IN no 30 de 21 de maio de 2008 (BRASIL, 2008) é a responsável por determinar os parâmetros de comercialização. Quando comparadas às grandes culturas, no entanto, as sementes de pastagem apresentam baixa qualidade física e fisiológica (ALVES et al., 2017).

Neste sentido, embora diversos estudos avaliem a qualidade física e fisiológica de sementes de Urochloa (FRANÇA-NETO, 2009; FONTANELI et al., 2012; SILVA, 2013; CARDOSO et al., 2014; BATISTA et al., 2016; SILVA et al., 2019), gênero com maior produção de sementes pelo Brasil, avaliações referentes ao gênero Megathyrsus ainda são limitadas. Em um dos poucos estudos de lotes de capimcolonião, Ohlson et al. (2010) avaliaram sementes do gênero comercializados no Estado do Paraná e verificaram que a maioria dos lotes não atendeu o padrão mínimo legal exigido quanto a pureza e que, neste caso, o teste de germinação não era nem realizado. No entanto, não há relatos acadêmicos de estudos realizados com sementes produzidas no Centro-Oeste brasileiro (MALLMANN, 2013), região com maior área e produção deste gênero (ROVERI, 2018).

Assim, o presente estudo teve como objetivo realizar um diagnóstico da qualidade física e fisiológica de sementes de três cultivares da espécie Megathyrsus maximus (Mombaça, 'BRS Tamani' e 'BRS Zuri') comercializadas por diferentes empresas de Campo Grande, MS.

\section{Material e Métodos}

Este estudo foi conduzido no Laboratório Didático de Análise de Sementes da Universidade Anhanguera-UNIDERP em maio de 2019. Foram avaliadas sementes da safra 20172018 da espécie Megathyrsus maximus, as cultivares Mombaça, BRS Tamani e BRS Zuri, comercializadas por seis empresas (procedências) situadas em Campo Grande - MS (município com maior número empresas que comercializam sementes de forrageiras tropicais). Para cada lote de sementes provenientes de cada empresa avaliou-se:

- Pureza (\%): determinada segundo as Regras para Análise de Sementes (RAS) (BRASIL, 2009), utilizando-se uma amostra de $10 \mathrm{~g}$ separada nos componentes: semente pura, outras sementes e material inerte. As demais avaliações foram realizadas a partir da porção de sementes puras obtidas neste teste;

- Peso de Mil Sementes (g): obtida pela avaliação da massa de oito repetições de 100 sementes, de acordo com a fórmula Peso de mil sementes $($ PMS $)=$ massa da amostra $\times 1.000 /$ $\mathrm{n}^{\mathrm{o}}$ total de sementes, de acordo com RAS (BRASIL, 2009).

- Após estas determinações iniciais, conduziu-se um experimento em delineamento inteiramente casualizado, em esquema fatorial 3 X 6, com três cultivares e seis procedências.

- Germinação (\%): avaliada conforme RAS (BRASIL, 2009). $\mathrm{O}$ teste foi conduzido utilizando-se quatro repetições de 100 sementes, dispostas sobre papel umedecido de acordo com o peso do papel vezes 2,5 , incubadas em câmara de germinação com temperatura de $20-35^{\circ} \mathrm{C}$ e fotoperíodo de 12 horas, sendo que a contagem de plântulas normais foi realizada aos 10 (primeira contagem) e 28 dias após semeadura. A porcentagem de germinação foi expressa pela porcentagem de plântulas normais contabilizadas aos 28 dias após montagem do teste. Não foram realizados tratamentos para superação da dormência;

- Valor cultural (\%): realizada com quatro repetições de 100 sementes, e utilizando-se a fórmula V.C. $=(\%$ germinação $\mathrm{x}$ $\%$ pureza) / 100 ;

- Tetrazólio (\%): realizado com quatro repetições de 100 sementes. As sementes foram seccionadas longitudinal e medianamente através do embrião e as duas metades foram imersas em solução de tetrazólio a $0,1 \%$ e mantidas em câmara escura, a $37^{\circ} \mathrm{C}$, por três horas. Após esse período, as sementes foram lavadas e avaliadas sob uma lupa, quanto à localização e intensidade da coloração, sendo classificadas individualmente em viáveis e não viáveis (BRASIL, 2009).

Para avaliar a existência de diferença da qualidade de sementes entre empresas e entre espécies, os dados foram submetidos à Análise de Variância e, em caso de significância as médias comparadas pelo teste de Tukey, a $1 \%$ de probabilidade. Os dados, quando necessário, foram transformados conforme preconizado por Santana e Ranal (2004) e a variável pureza e peso de mil não foram analisadas estatisticamente, mas de acordo com o que estabelece as RAS (BRASIL, 2009).

\section{Resultados e Discussão}

A média da pureza das sementes comercializadas de capim-colonião é bastante semelhante entre as cultivares avaliadas, variando entre 83 e $89 \%$ (Quadro 1). Embora todos os lotes avaliados atendam a legislação vigente (BRASIL, 2008), apresentando pureza superior a 40\%, é válido ressaltar a discrepância de qualidade das sementes fornecidas pela empresa três, que apresenta valores inferiores às demais procedências para todas as cultivares avaliadas. Embora seja esperado que a pureza de lotes de forrageiras seja baixo devido a ampla variação do estádio de desenvolvimento das sementes em qualquer momento do ciclo reprodutivo da planta (SOUZA, 2001), os resultados deste estudo mostram altos percentuais encontrados para a maioria das empresas. Este fato pode denotar uma melhoria nos processos de produção, principalmente nos processos de colheita (MASCHIETTO et al., 2003) e beneficiamento (MELO et al., 2016).

Quadro 1 - Pureza (\%) de sementes de Megathyrsus maximus, cultivares Mombaça, BRS Zuri e BRS Tamani, provenientes de seis empresas estabelecidas no comércio de Campo Grande - MS em 2019

\begin{tabular}{|c|c|c|c|}
\hline \multirow{2}{*}{ Procedência } & \multicolumn{3}{|c|}{ Cultivar } \\
\cline { 2 - 4 } & Mombaça & BRS Zuri & BRS Tamani \\
\hline 1 & 95,7 & 92,4 & 97,2 \\
\hline 2 & 96,5 & 80,9 & 93,0 \\
\hline 3 & 64,3 & 49,0 & 49,3 \\
\hline 4 & 94,2 & 94,1 & 96,3 \\
\hline 5 & 91,4 & 90,3 & 91,2 \\
\hline 6 & 92,0 & 95,2 & 93,4 \\
\hline $\begin{array}{c}\text { Média } \pm \\
\text { desvio padrão }\end{array}$ & $89,0 \pm 12,3$ & $83,7 \pm 17,7$ & $86,7 \pm 18,5$ \\
\hline
\end{tabular}

Fonte: Dados da pesquisa 
O peso de 1.000 sementes apresentou pequena variação entre cultivares e empresas (Quadro 2). Este é um parâmetro que pode ser utilizado para estimar a qualidade de lotes de sementes já que a viabilidade das mesmas apresenta valores máximos na maturidade fisiológica, que é definida pela massa máxima que a semente atinge no seu processo de maturação (LAURA et al., 2009). Esta variável é conhecida já no lançamento de cada cultivar. Segundo Cecon et al. (2015) o peso médio de 1.000 semente das cultivares Mombaça, Zuri e Tamani são, respectivamente, 1,52, 1,72 e 1,11 g. Relacionando esses valores aos encontrados no presente estudo é possível afirmar que as condições dos campos de produção de sementes estão adequadas para que as cultivares Mombaça e Tamani expressem o seu potencial genético, uma vez que as sementes produzidas apresentam peso dentro do esperado para as diferentes cultivares.

Quadro 2 - Peso de 1.000 sementes (g) de Megathyrsus maximus, cultivares Mombaça, BRS Zuri e BRS Tamani, provenientes de seis empresas estabelecidas no comércio de Campo Grande - MS em 2019

\begin{tabular}{|c|c|c|c|}
\hline \multirow{2}{*}{ Procedência } & \multicolumn{3}{|c|}{ Cultivar } \\
\cline { 2 - 4 } & Mombaça & BRS Zuri & BRS Tamani \\
\hline 1 & 1,510 & 1,445 & 1,465 \\
\hline 2 & 1,295 & 1,330 & 1,390 \\
\hline 3 & 1,390 & 1,525 & 1,205 \\
\hline 4 & 1,439 & 1,433 & 1,455 \\
\hline 5 & 1,560 & 1,535 & 1,540 \\
\hline 6 & 1,425 & 1,340 & 1,355 \\
\hline $\begin{array}{c}\text { Média } \pm \\
\text { desvio padrão }\end{array}$ & $1,44 \pm 0,09$ & $1,43 \pm 0,09$ & $1,40 \pm 0,12$ \\
\hline
\end{tabular}

Fonte: Dados da pesquisa

A primeira contagem do teste de germinação variou tanto em função das espécies como em função das procedências avaliadas (interação significativa, $\mathrm{p}<0,001$ ) (Quadro 3). A cultivar Mombaça foi a que, em média, apresentou resultados superiores para a primeira contagem, embora tenha apresentado também a maior variação entre empresas $(6,3$ vezes). As demais cultivares apresentaram menor variação para este parâmetro entre empresas, de 1,7 e 1,6 vezes respectivamente para Zuri e Tamani.

Quadro 3 - Primeira contagem (\%) do teste de germinação de Megathyrsus maximus, cultivares Mombaça, BRS Zuri e BRS Tamani, provenientes de seis empresas estabelecidas no comércio de Campo Grande - MS em 2019

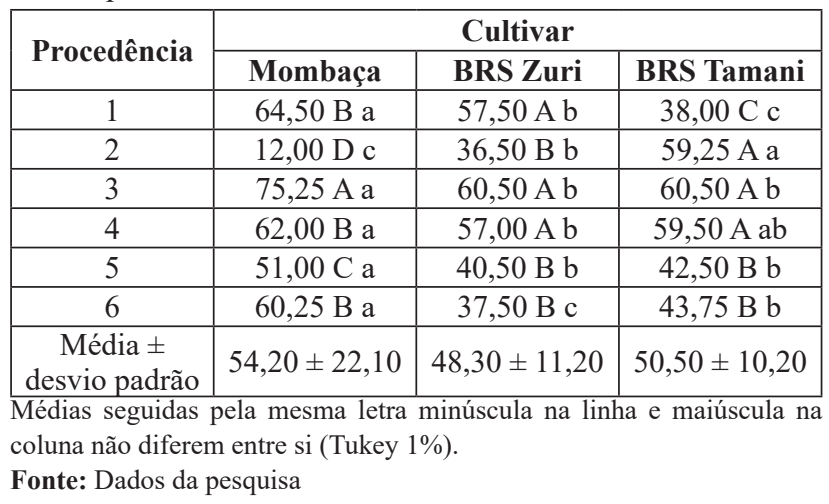

Embora a cultivar Mombaça tenha apresentado, de maneira geral, germinação mais rápida do que as demais, ao final do teste de germinação as três cultivares apresentaram porcentagem semelhante, em torno de $60 \%$, quando considerada a média de todas as procedências (Quadro 4). No entanto, destaca-se novamente a discrepância de resultados encontrados entre empresas para a cultivar Mombaça, apresentando entre $17 \%$ (procedência 2) e 78\% (procedência 3). Somente no caso pontual da procedência 2 não se tem o cumprimento da legislação para o comércio das sementes, sendo que o mínimo de germinação exigida é de 40\% (BRASIL, 2008). Contudo, de acordo com Marcos-Filho (1999) e Malone et al. (2008), é importante ressaltar que os resultados da análise da primeira contagem do teste de germinação indicam diferenças entre lotes em relação ao vigor de sementes. Neste sentido é possível afirmar que sementes de Mombaça, com exceção do lote da procedência 2, teriam maior potencial de estabelecer rapidamente um estande uniforme no campo, apresentando melhores condições de competir por recursos com espécies de daninhas que venham a se estabelecer durante a formação da pastagem (MARCOS-FILHO, 2015).

Quadro 4 - Germinação (\%) de sementes de Megathyrsus maximus, cultivares Mombaça, BRS Zuri e BRS Tamani, provenientes de seis empresas estabelecidas no comércio de Campo Grande - MS em 2019

\begin{tabular}{|c|c|c|c|}
\hline \multirow{2}{*}{ Procedência } & \multicolumn{3}{|c|}{ Cultivar } \\
\cline { 2 - 4 } & Mombaça & BRS Zuri & BRS Tamani \\
\hline 1 & $68 \mathrm{~B} \mathrm{a}$ & $60 \mathrm{~B} \mathrm{~b}$ & $52 \mathrm{D} \mathrm{c}$ \\
\hline 2 & $17 \mathrm{C} \mathrm{c}$ & $42 \mathrm{C} \mathrm{b}$ & $63 \mathrm{BC} \mathrm{a}$ \\
\hline 3 & $78 \mathrm{~A} \mathrm{a}$ & $71 \mathrm{~A} \mathrm{~b}$ & $64 \mathrm{~B} \mathrm{c}$ \\
\hline 4 & $69 \mathrm{~B} \mathrm{~ns}$ & $68 \mathrm{~A} \mathrm{~ns}$ & $71 \mathrm{~A} \mathrm{~ns}$ \\
\hline 5 & $68 \mathrm{~B} \mathrm{~b}$ & $67 \mathrm{~A} \mathrm{~b}$ & $60 \mathrm{C} \mathrm{a}$ \\
\hline 6 & $67 \mathrm{~B} \mathrm{a}$ & $57 \mathrm{~B} \mathrm{c}$ & $62 \mathrm{BC} \mathrm{b}$ \\
\hline $\begin{array}{c}\text { Média } \pm \\
\text { desvio padrão }\end{array}$ & $61,2 \pm 22,0$ & $60,8 \pm 10,6$ & $62,0 \pm 10,2$ \\
\hline
\end{tabular}

Médias seguidas pela mesma letra minúscula na linha e maiúscula na coluna não diferem entre si (Tukey $1 \%$ ).

Fonte: Dados da pesquisa

Segundo as Regras para Análise de Sementes (BRASIL, 2009), a informação do resultado do teste de germinação desta espécie é fornecida após 28 dias. Neste sentido, com a finalidade de reduzir o tempo para a obtenção do resultado da análise dos lotes de sementes, a Instrução Normativa do MAPA $n^{\circ} 30$ de 26/10/2010 (BRASIL, 2010) flexibilizou a comercialização com base nos resultados de viabilidade obtidos pelo Teste de Tetrazólio. Desta forma, obtêm-se informações sobre a qualidade das sementes em um período de 36 horas. Analisando-se, no entanto, os resultados do teste de tetrazólio (Quadro 5) em relação aos do teste de germinação percebe-se que há incremento de $40 \%$ no primeiro em relação ao segundo. Assim, destaca-se a relevância em relação à interpretação do Teste de Tetrazólio, uma vez que a coloração dos tecidos embrionários indicando viabilidade, não necessariamente resultarão na emergência de uma plântula normal no campo (BRASIL, 2009). 
Quadro 5 - Sementes viáveis (\%) avaliadas pelo teste de tetrazólio de Megathyrsus maximus, cultivares Mombaça, BRS Zuri e BRS Tamani, provenientes de seis empresas estabelecidas no comércio de Campo Grande - MS em 2019

\begin{tabular}{|c|c|c|c|}
\hline \multirow{2}{*}{ Procedência } & \multicolumn{3}{|c|}{ Cultivar } \\
\cline { 2 - 4 } & Mombaça & BRS Zuri & BRS Tamani \\
\hline 1 & $95 \mathrm{Aa}$ & $78 \mathrm{C} \mathrm{c}$ & $82 \mathrm{C} \mathrm{b}$ \\
\hline 2 & $65 \mathrm{E} \mathrm{c}$ & $70 \mathrm{D} \mathrm{b}$ & $90 \mathrm{~A} \mathrm{a}$ \\
\hline 3 & $90 \mathrm{~B} \mathrm{~ns}$ & $89 \mathrm{~A} \mathrm{~ns}$ & $89 \mathrm{~A} \mathrm{~ns}$ \\
\hline 4 & $81 \mathrm{D} \mathrm{c}$ & $84 \mathrm{~B} \mathrm{~b}$ & $86 \mathrm{~B} \mathrm{a}$ \\
\hline 5 & $90 \mathrm{~B} \mathrm{a}$ & $89 \mathrm{~A} \mathrm{a}$ & $85 \mathrm{~B} \mathrm{~b}$ \\
\hline 6 & $84 \mathrm{C} \mathrm{b}$ & $88 \mathrm{~A} \mathrm{a}$ & $82 \mathrm{C} \mathrm{c}$ \\
\hline $\begin{array}{c}\text { Média } \pm \text { desvio } \\
\text { padrão (2019) }\end{array}$ & $84,2 \pm 10,6$ & $83,0 \pm 7,6$ & $85,7 \pm 3,4$ \\
\hline
\end{tabular}

Médias seguidas pela mesma letra minúscula na linha e maiúscula na coluna não diferem entre si (Tukey $1 \%$ ).

Fonte: Dados da pesquisa

As sementes do gênero Megathyrsus são comercializadas com base no valor cultural, que leva em consideração os resultados da análise de pureza e de germinação (BRASIL, 2010). A análise do valor cultural revelou que das seis empresas avaliadas, quatro não apresentaram diferenças entre cultivares (Quadro 6), demonstrando novamente, a importância na escolha da procedência. Quando se avalia, no entanto, diferenças entre empresas dentro de uma mesma cultivar, nota-se que a escolha entre as piores e melhores procedências (empresas) pode resultar em um ganho de qualidade física e fisiológica nas sementes de até 2,3, 1,8 e 2,2 vezes, respectivamente, para Mombaça, Zuri e Tamani.

Quadro 6 - Valor cultural (\%) de sementes de Megathyrsus maximus, cultivares Mombaça, BRS Zuri e BRS Tamani, provenientes de seis empresas estabelecidas no comércio de Campo Grande - MS em 2019

\begin{tabular}{|c|c|c|c|}
\hline \multirow{2}{*}{ Procedência } & \multicolumn{3}{|c|}{ Cultivar } \\
\cline { 2 - 4 } & Mombaça & BRS Zuri & BRS Tamani \\
\hline 1 & $65,08 \mathrm{~A} \mathrm{~ns}$ & $55,44 \mathrm{AB} \mathrm{ns}$ & $50,54 \mathrm{~B} \mathrm{~ns}$ \\
\hline 2 & $31,98 \mathrm{~B} \mathrm{a}$ & $40,59 \mathrm{BC}$ ab & $55,29 \mathrm{~B} \mathrm{~b}$ \\
\hline 3 & $28,3 \mathrm{~B} \mathrm{a}$ & $34,79 \mathrm{C} \mathrm{ab}$ & $50,2 \mathrm{AB} \mathrm{b}$ \\
\hline 4 & $50,15 \mathrm{AB} \mathrm{ns}$ & $34,79 \mathrm{C} \mathrm{ns}$ & $31,55 \mathrm{~A} \mathrm{~ns}$ \\
\hline 5 & $65 \mathrm{~A} \mathrm{~ns}$ & $63,99 \mathrm{~A} \mathrm{~ns}$ & $68,37 \mathrm{~B} \mathrm{~ns}$ \\
\hline 6 & $62,19 \mathrm{~A} \mathrm{~ns}$ & $61,06 \mathrm{~A} \mathrm{~ns}$ & $58,66 \mathrm{~B} \mathrm{~ns}$ \\
\hline $\begin{array}{c}\text { Média } \pm \text { desvio } \\
\text { padrão (2019) }\end{array}$ & $50,5 \pm 16,7$ & $48,4 \pm 13,3$ & $52,4 \pm 12,2$ \\
\hline
\end{tabular}

Médias seguidas pela mesma letra minúscula na linha e maiúscula na coluna não diferem entre si (Tukey $1 \%$ ).

Fonte: Dados da pesquisa

Quando o pecuarista faz a escolha de um material genético (cultivares) baseia-se em características de interesse agronômico. Por exemplo, a cultivar Zuri destacase das outras cultivares de capim-colonião pela resistência ao fungo Bipolaris maydis, que causa manchas em suas folhas, enquanto a cultivar Tamani é a melhor indicação para ovinos e equinos, devido ao seu baixo porte e folhas e colmos mais finos (EMBRAPA, 2019). Contudo, isto não é suficiente para garantir o efetivo estabelecimento do estande no campo, tornando-se imprescindível a escolha adequada da procedência. Este estudo mostrou que, apesar de o gênero avaliado apresentar qualidade física e fisiológica que atende à legislação vigente, é possível encontrar lotes com qualidade distinta no mercado de um mesmo município. Assim, a escolha adequada da procedência (empresa) vai garantir a expressão máxima do potencial genético, subsidiada por processos adequados de produção e pós-colheita.

\section{Conclusão}

Com exceção de um lote da cultivar Mombaça, os demais lotes das três cultivares da espécie Megathyrsus maximus (Mombaça, 'BRS Tamani' e 'BRS Zuri'), de todas as procedências avaliadas, apresentam qualidade física $\mathrm{e}$ fisiológica compatível com a comercialização em função da legislação vigente.

\section{Referências}

ABRASEM - Associação Brasileira de Sementes e Mudas. Brasília. Estatística: Produção de sementes de gramíneas forrageiras. Disponível em: http://www.abrasem.com.br/ estatisticas/\#. Acesso em: 30 jul. 2019.

ALVES, B.A. et al. Germinação de sementes de forrageiras do gênero Brachiaria em função dos ambientes e tempos de armazenamento. Global Scie. Technol., v.10, n.1, p,11-19, 2017.

BATISTA, V.T.; NUNES, J.V. D.; NÓBREGA, L. H. P. Qualidade fisiológica de sementes de Brachiaria brizantha cv. marandu com variação nas características de pureza. Rev. Agricul., v.91, n.1, p.92-100, 2016. doi: 10.37856/bja.v91i1.228.

BRASIL. Instrução Normativa $n^{\circ} 30$, de 21 de maio de 2008. Estabelece normas e padrões para produção e comercialização de sementes de espécies forrageiras de clima tropical. Diário Oficial da União: seção 1, Brasília, DF, 23 mai. 2008.

BRASIL. Lei $\mathrm{n}^{\circ} 10.711$, de 5 de agosto de 2003. Dispõe sobre o Sistema Nacional de Sementes e Muda e dá outras providências. Diário Oficial da União: seção1, Brasília, DF, 06 ago. 2003.

BRASIL, Ministério da Agricultura, Pecuária e Abastecimento. Regras para análise de sementes. Brasília: MAPA, 2009.

BRASIL. Instrução Normativa ${ }^{\circ} 30$, de 26 de outubro de 2010. Altera Instrução Normativa MAPA n ${ }^{\circ} 30$ de 2008, que estabelece normas e padrões para produção e comercialização de sementes de espécies forrageiras de clima tropical. Diário Oficial da União: seção 1, Brasília, DF, 27 out. 2010.

CANTO, M. W. et al. Produção e qualidade de sementes do capimmombaça em função da adubação nitrogenada. Bragantia, v.71, n.3, p.430-437, 2012. doi: 10.1590/S0006-87052012005000032.

CARDOSO, E. D. et al. Desempenho fisiológico e superação de dormência em sementes de Brachiaria brizantha submetidas a tratamento químico e envelhecimento artificial. Semina: Ciênc. Agrárias, v.35, n. 1, p. 21-38, 2014. doi: 10.5433/1679-0359.2014v35n1p21.

CECON, G. et al. Implantação e manejo de forrageiras em consórcio com milho safrinha. Dourados: Embrapa Agropecuária Oeste, 2015. 17p. (Boletim Técnico, 131).

EMBRAPA - Empresa Brasileira de Pesquisa Agropecuária. Aplicativo com o catálogo das Cultivares de Forrageiras Tropicais da Embrapa e de Domínio Público. Disponível em: http://www.pastocerto.com/. Acesso em: 25 mar. 2019.

FONTANELI, R.S.; SANTOS, H.P.; FONTANELI, R.S. Forrageiras para integração lavoura-pecuária-floresta na Região Sul-brasileira. Brasília: EMBRAPA, 2012. 274 p. 
FRANÇA-NETO, J.B. Evolução do conceito de qualidade de sementes. Informativo ABRATES, Londrina, v. 19, n. 2, p. 76-80, 2009.

GARCEZ, B. S. et al. Degradabilidade ruminal do capim colonião (Panicum maximum Jacq. cv. Colonião) em três idades pós-rebrota. Acta Vet. Brasilica, v.10, n.2, p.130-134, 2016. doi: 10.21708/avb.2016.10.2.5513.

LAURA, V.A. et al. Qualidade física e fisiológica de sementes de braquiárias comercializadas em Campo Grande - MS. Ciênc. Agrotecnol., v.33, n.1, p.326-332, 2009. doi: 10.1590/S141370542009000100045 .

LIMA, D.M. et al. Morphological characteristics, nutritive quality, and methane production of tropical grasses in Brazil. Pesq. Agrop. Bras.v.53, n.3, p.323-331, 2018. doi: 10.1590/ S0100-204X2018000300007.

MALONE, P.F.V.A.; VILELLA, F.A.; MAUCH, C.R. Potencial fisiológico de sementes de mogango e desempenho das plântulas no campo. Rev. Bras. Sementes, v.30, n.2, p.123-130, 2008. doi: 10.1590/S0101-31222008000200015.

MARCOS FILHO, J. Testes de vigor: importância e utilização. In: KRZYZANOWSKI, F.C.; VIEIRA, R.D.; FRANÇA-NETO, J.B. (Ed.). Vigor de sementes: conceitos e testes. Londrina: ABRATES, 1999. p. 1.1-1.21.

MARCOS FILHO, J. Fisiologia de sementes de plantas cultivadas. Londrina: ABRATES, 2015.

MASTROCOLA, M.A.; MARCOS FILHO, J. Armazenamento de sementes de capim-colonião. Pesquisa Agropecuária Brasileira, Brasília, v. 19, n. 5, p. 519-527, 1984.

MASCHIETTO, R.W.; NOVEMBRE, A.D.L.C.; SILVA, W.R. Métodos de colheita e qualidade das sementes de capim colonião cultivar Mombaça. Bragantia, v.62, n.2, p.291-296, 2003. doi: 10.1590/S0006-87052003000200015.
MALLMANN, G. et al. Fungos e nematoides associados a sementes de forrageiras tropicais. Summa Phytopathol., v.39, n.3, p.201-203, 2013. doi: 10.1590/S0100-54052013000300010.

MELO, L.F. et al. Beneficiamento na qualidade física e fisiológica de sementes de capim-mombaça. Rev. Ciênc. Agronômica, v.47, n.4, p.667-674, 2016.

MENDONÇA, V.Z. et al. Corn production for silage intercropped with forage in the farming-cattle breeding integration. Rev. Eng. Agric.,, v.34, n.4, p.738-745, 2014. doi: 10.1590/S010069162014000400013.

OHLSON, O.C.; SOUZA, C.R.; PANOBIANCO, M. Qualidade física e fisiológica de sementes de capim-colonião e milheto, comercializadas no estado do Paraná. Informativo Abrates, v.20, n.1,2, p. 30-36, 2010.

ROVERI, M. Informações setor forrageiras tropicais NCM 12092900 [mensagem pessoal]. Mensagem recebida por <daiane@germipasto.com.br>em 23 ago. 2018.

SANTANA, D. G.; RANAL, M. A. Análise da germinação: um enfoque estatístico. Brasília: UnB, 2004.

SILVA, G. M. Qualidade de sementes forrageiras. Bagé: Embrapa Pecuária Sul, 2013.

SILVA, G.Z. et al. Production regions and physical quality of Urochloa decumbens cv. Basilisk seeds. Biosci. J., v.35, n. 1, p.236-243, 2019. doi: 10.14393/BJ-v35n1a2019-41749.

SOUZA, F. H. D. Produção de sementes de gramineas forrageiras tropicais. São Carlos: Embrapa Sudeste, 2001.

STABILE, S.S. et al. Características de produção e qualidade nutricional de genótipos de capim colonião colhidos em três estádios de maturidade. Rev. Bras. Zootec., v.39, n.7, p.14181428, 2010. doi:10.1590/S1516-35982010000700004. 